\title{
Enhanced Phytoremediation of Pb-contaminated Soil with $\beta$-Cyclodextrin
}

\author{
L.D. $\mathrm{GAO}^{1}$ \& R.J. $\mathrm{ZHENG}^{1} \& \mathrm{~T}$. $A \mathrm{~N}^{1}$ \\ S. ZHANG ${ }^{2} \&$ M.L. PANG ${ }^{2}$ \\ ${ }^{1}$ College of Chemistry and Chemical Engineering, Qiqihar University, Heilongjiang, China \\ ${ }^{2}$ Department of Chemistry and Chemical Engineering, Faculty of Engineering, Niigata University, \\ Niigata, Japan
}

\begin{abstract}
KEYWORD: Phytoremediation; $\beta$-Cyclodextrin; Soil contamination; Lead; Braissca juncea ABSTRACT: Phytoremediation of Pb-contaminated soil was studied with $\beta$-cyclodextrin as enhancing agent using Brassica Juncea. Effects of the addition dosage and the addition time of $\beta$ cyclodextrin, and $\mathrm{Pb}$ concentration in soil on the plant growth were investigated. Plants were cultivated in an environmental control system. Biomass of all plant was weighed, and $\mathrm{Pb}$ concentrations in shoot and root were determined using ICP-MS. The results show that $\beta$-cyclodextrin enhance the phytoremediation effect of $\mathrm{Pb}$-contaminated soil, the biomass of Brassica juncea is affected mainly by $\mathrm{Pb}$ concentration in soil and the addition time of $\beta$-cyclodextrin, and the addition dosage of $\beta$ cyclodextrin has the minimum effect.
\end{abstract}

\section{INTRODUCTION}

With the rapid development of urbanization and industrialization, soils have been heavily polluted by metals. Lead $(\mathrm{Pb})$ is one of the five most common heavy metals found at contaminated soils. $\mathrm{Pb}$ accumulation in soils has been shown to cause a variety of environmental problems (Saifullah et al., 2009; Lin et al., 2009).

Phytoremediation is a cleanup technology of contaminated soils with the advantages of cost-effective and environmental-friendly (Ma et al., 2011; Nicoletta \& Flavia, 2011; Magdalena et al., 2011). Brassica juncea is a hyperaccumulators for $\mathrm{Pb}$. However, it still presents weakly on biomass production, accumulation and translocation capacity of $\mathrm{Pb}$, which limits its applications in field. Thus, it is necessary to improve phytoremediation efficiency of hyperaccumulators.

Here, $\beta$-cyclodextrin was selected as enhancing agent because of its structural features including hydrophobic cavities and hydrophilic surface, and/or its properties and merits of foaming, dispersion, coating, de-emulsification, easy availability, acceptable lower cost, environmental compatibility, biodegradation, and so on. Considering the above-mentioned, the objective of this work is to evaluate the potential enhanced effect of $\beta$-cyclodextrin on phytoremediation of $\mathrm{Pb}$-contaminated soil by Brassica juncea.

\section{MATERIALS AND METHODS}

\section{Chemicals}

$\beta$-cyclodextrin was obtained from Tianjin Kemiou Chemical Reagent Co. Ltd. (China). Nitrate lead, $\mathrm{Pb}\left(\mathrm{NO}_{3}\right)_{2}$, was purchased from Tianjin Kaitong Chemical Reagent Co. Ltd. (China). Pb standard solutions used for making the calibration curve were prepared by diluting the standard solutions (1000 mg $\cdot \mathrm{dm}^{-3}$ in $5 \% \mathrm{HNO}_{3}$ solution) purchased from Beijing Shengshi Kangpu Chemical Technology Institute (China). All chemical reagents used were of analytical grade. Ultrapure water $(>18.2$ $\mathrm{M} \Omega$ ), was used throughout the work. The nutrient solution was prepared by dissolving $\mathrm{KH}_{2} \mathrm{PO}_{4}$, $\mathrm{KNO}_{3}$ and $\mathrm{CO}\left(\mathrm{NH}_{2}\right)_{2}$ in ultrapure water, then used as fertilizer during the period of the plant cultivation.

Soil

Expanded Vermiculite (Lingshou, Hebei Province, China) was used as the tested soil, which has high moisture retention capability, air capacity and nutrient preserving capability. The characters of soil 
measured in our work are as follows: $\mathrm{pH} 7.1,0.52 \%$ of organic matter, $39.1 \mathrm{cmol} \cdot \mathrm{kg}^{-1}$ of cation exchange capacity and $2.7 \mathrm{mg} \cdot \mathrm{kg}^{-1} \mathrm{~Pb}$.

$\mathrm{Pb}$-contaminated soil was prepared by adding slowly the solution containing $\mathrm{Pb}\left(\mathrm{NO}_{3}\right)_{2}$ to a certain amount Expanded Vermiculite to avoid the metal solution run off from the soil, then stirred well and air-dried. The soil of three treatments $\left(200,500\right.$ and $\left.1000 \mathrm{mg} \cdot \mathrm{kg}^{-1} \mathrm{~Pb}\right)$ was obtained.

\section{Pot experiment}

The soil was filled $500 \mathrm{~mL}$ plastic pots ( $300 \mathrm{~g}$ soil per pot) and moistened with ultrapure water to reach approximately $80 \%$ water holding capacity. Each pot was planted with five seeds of Brassica juncea, and germinated in the plant environmental control system (RTOP-300D, Zhejiang TOP Instrument Co. Ltd., China) under the controlled conditions: day and night temperatures were on average $26^{\circ} \mathrm{C}$ and $20^{\circ} \mathrm{C}$, respectively, in a 12/12h day night cycle. Light density was $7500 \mathrm{~lx}$, and relative humidity was remained $60 \%$. The above-mentioned nutrient solution was used as basal fertilizers to supply nitrogen $(\mathrm{N})$, phosphate $(\mathrm{P})$ and potassium $(\mathrm{K})$ for plants. Pots were watered every day with the nutrient solution and ultrapure water according to water loss by weight to maintain $80 \%$ of water holding capacity. Following seedling emergence, the pots were thinned to one plant per pot. Addition dosage and addition time of $\beta$-cyclodextrin were investigated, that is, after sowing (1st week), at exuberant growth period (4th week) and before harvesting ( 7 th week), $\beta$ cyclodextrin were added with the dosage of $0.5,1.0$ and $2.0 \mathrm{~g} \cdot \mathrm{kg}^{-1}$ soil, respectively. They were applied to the soil surface as solutions. An orthogonal experiment of $L_{9}\left(3^{3}\right)$ was applied (Table 1). In addition, the pot without $\beta$-cyclodextrin and $\mathrm{Pb}$ was kept as a blank. Each treatment was performed in triplicate with a random block design, thus, 30 pots were used.

\section{Extraction and Determination of $\mathbf{P b}$}

Brassica juncea were harvested after 8 weeks growth by cutting stems $1 \mathrm{~cm}$ above the soil surface. The above-ground parts are considered as "shoot" and the parts below the ground are as "root". Shoot and root samples were washed carefully with ultrapure water after tap water to remove any soil splash, and were oven-dried at $80^{\circ} \mathrm{C}$ for $24 \mathrm{~h}$, and weighed then ground in a mortar. Dried plant samples $\left(0.1 \mathrm{~g}\right.$ of each sample) were digested with $10 \mathrm{~mL}$ conc. $\mathrm{HNO}_{3}(60-61 \%)$ and $3.0 \mathrm{~mL}$ conc. HF (46-48\%) in a microwave digestion instrument (MDS-6, Shanghai Sineo Microwave Chemistry Technology Co. Ltd., China). The suspension including digested samples was evaporated on the hot plate, and then diluted to $50 \mathrm{~mL}$ with $1 \mathrm{~mol} \cdot \mathrm{L}^{-1} \mathrm{HNO}_{3}$ solution. $\mathrm{Pb}$ concentration was determined by ICP-MS (Agilent 7500ce, America).

Table 1. Conditions of pot experiments.

\begin{tabular}{|c|c|c|c|}
\hline $\begin{array}{l}\text { Pot } \\
{[\text { No. }} \\
]\end{array}$ & $\begin{array}{l}\mathrm{Pb} \\
{\left[\mathrm{mg} \cdot \mathrm{kg}^{-}\right.} \\
1]\end{array}$ & $\begin{array}{l}\beta- \\
\text { cyclodextrin } \\
{\left[\mathrm{g} \cdot \mathrm{kg}^{-1}\right]}\end{array}$ & $\begin{array}{l}\text { Addition time of } \\
\beta \text {-cyclodextrin } \\
{[\text { week }]}\end{array}$ \\
\hline 0 & 0 & 0 & -- \\
\hline 1 & 200 & 0.5 & $1 \mathrm{st}$ \\
\hline 2 & 500 & 1.0 & 7 th \\
\hline 3 & 1000 & 2.0 & 4th \\
\hline 4 & 200 & 1.0 & 4th \\
\hline 5 & 500 & 0.5 & 4 th \\
\hline 6 & 1000 & 0.5 & 7 th \\
\hline 7 & 200 & 2.0 & 7 th \\
\hline 8 & 500 & 2.0 & $1 \mathrm{st}$ \\
\hline 9 & 1000 & 1.0 & $1 \mathrm{st}$ \\
\hline
\end{tabular}

\section{Data analysis}

Biomass were analyzed by direct-viewing analysis method as well as concentration and total uptake amount of $\mathrm{Pb}$ in shoot and root of Brassica juncea according to Table 1 (Data were not listed here). 


\section{RESULTS AND DISCUSSION}

\section{Biomass}

The shoot and root biomass (dry weight) of Brassica juncea in all pots after 8 weeks growth are shown in Figure 1. All plant can grow normally in contaminated soil investigated. In the absence of $\beta$-cyclodextrin, however, the biomass of the pots introducing $\mathrm{Pb}$ exhibit clearly reduction compared with that of the blank, which indicates that excess $\mathrm{Pb}$ only inhibit the plant growth, and is nontoxic to plant (Li et al., 2007). On the other hand, the shoot biomass increases with the increase of $\mathrm{Pb}$ concentration in soil. From these experiments, it can be observed that the addition of $\beta$-cyclodextrin has no obvious effect on the biomass although biomass is the minimum with $2.0 \mathrm{~g} \cdot \mathrm{kg}^{-1} \beta$-cyclodextrin, and that the addition of $\beta$-cyclodextrin can enhance the growth of Brassica juncea on the1st week. These results suggest that the biomass is mainly affected by the addition time of $\beta$-cyclodextrin following to the concentration of $\mathrm{Pb}$ in soil.

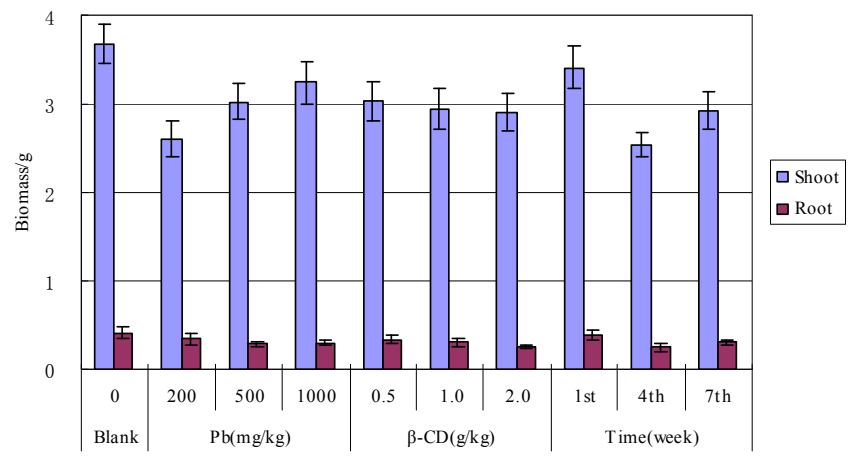

Figure 1. Biomass in shoot and root of Brassica Juncea.

\section{Pb Concentration in Shoot and Root}

The concentrations of $\mathrm{Pb}$ in shoot and root of Brassica juncea are shown in Figure 2. The following matters were obtained: (1) $\mathrm{Pb}$ concentration in plant increased generally with the increase of $\mathrm{Pb}$ concentration in soil, and the concentration in root is much higher than that in shoot. It shows that $\mathrm{Pb}$ is easy to be accumulated in root of Brassica juncea, and that the translocation amount of $\mathrm{Pb}$ is small from root to shoot. In addition, a good linear relationship is found between any two of the three $\mathrm{Pb}$ concentration in soil, shoot and root $\left(\mathrm{R}^{2}>0.99\right)$, which indicates $\mathrm{Pb}$ is absorbed and transferred according to the same mechanism regardless of $\mathrm{Pb}$ concentration in soil. (2) $\mathrm{Pb}$ concentration in shoot and root is elevated when $\beta$-cyclodextrin concentration is large, especially in case of pots with the addition of $2.0 \mathrm{~g} \cdot \mathrm{kg}^{-1} \beta$-cyclodextrin, the $\mathrm{Pb}$ average concentrations are $311.882 \mathrm{mg} / \mathrm{kg}$ and $8.824 \mathrm{mg} / \mathrm{kg}$ in root and shoot, respectively. It shows that $\beta$-cyclodextrin improves $\mathrm{Pb}$ absorbption from the rhizosphere and $\mathrm{Pb}$ transport from root to shoot. These results may be caused by the properties and/or structural features of $\beta$-cyclodextrin with foaming, dispersion, coating, deemulsification, hydrophobic cavities, hydrophilic surface and so on. These make $\beta$-cyclodextrin may form complexes with metals at the soil interface, leading to metal into the soil solution to increase metals absorption. In addition, $\beta$-cyclodextrin leads to a more efficient uptake of metallic elements due to increasing the permeability of the cell membrane, and enhance the translocation of metals from root to shoot by increasing the transpiration. These are possible mechanisms of enhancing phytoremediation of soil contaminated by $\mathrm{Pb}$ with $\beta$-cyclodextrin. (3) For the addition time of $\beta$ cyclodextrin, it is suggested that the concentration of $\mathrm{Pb}$ in root is the highest when $\beta$-cyclodextrin is added at exuberant growth period (4th week), and the concentration of $\mathrm{Pb}$ in shoot is the highest adding $\beta$-cyclodextrin before harvesting (7th week). 


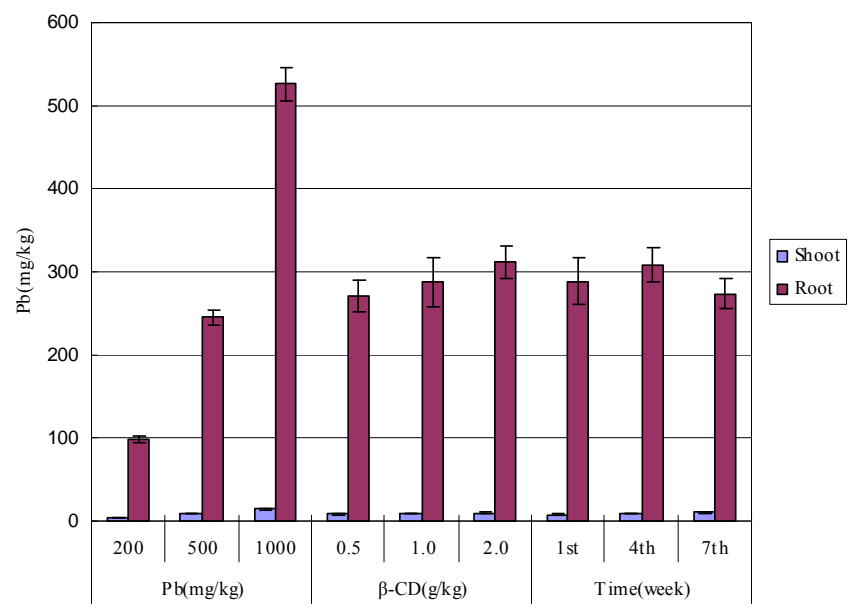

Figure 2. $\mathrm{Pb}$ concentrations in shoot and root of Brassica juncea.

The ratios of metal concentration in shoot to the concentration in soil (i.e., bioaccumulation factors, $\mathrm{BAF}$ ) and to the concentration in root of plant (i.e., translocation factors, TF), reflect directly the absorption and translocation ability of metal from soil to shoot and root to shoot, respectively. Then, the $\mathrm{BAF}$ and $\mathrm{TF}$ of $\mathrm{Pb}$ is calculated (Data are not shown here.). It is found that the BAF and TF ascended with the increase of $\mathrm{Pb}$ concentration in soil, which shows that Brassica juncea has strong remediation ability for the soil with lower $\mathrm{Pb}$ concentration. The later $\beta$-cyclodextrin is added, the higher $\mathrm{TF}$ is.

\section{Total Uptake Amount of Pb in Shoot and Root}

Total uptake amount of $\mathrm{Pb}$ in shoot and root is calculated according to $\mathrm{Pb}$ concentration in shoot (or root) and biomass of shoot (or root). It elevated with the increase of Pb concentration in soil (Fig. $3)$. It increases with the increase of $\mathrm{Pb}$ concentration in soil which is accords with the biomass and $\mathrm{Pb}$ concentration in Brassica juncea. Total uptake amount reached the minimum when $\beta$ cyclodextrin was added on the 4th week, respectively. In addition, for the additional dosage of $\beta$ cyclodextrin, the total uptake amount has little change. However, the interaction among influence factors was not definitely elucidated in this study, then, further studies are needed to confirm the interaction for finding out the optimum additional dosage of $\beta$-cyclodextrin.

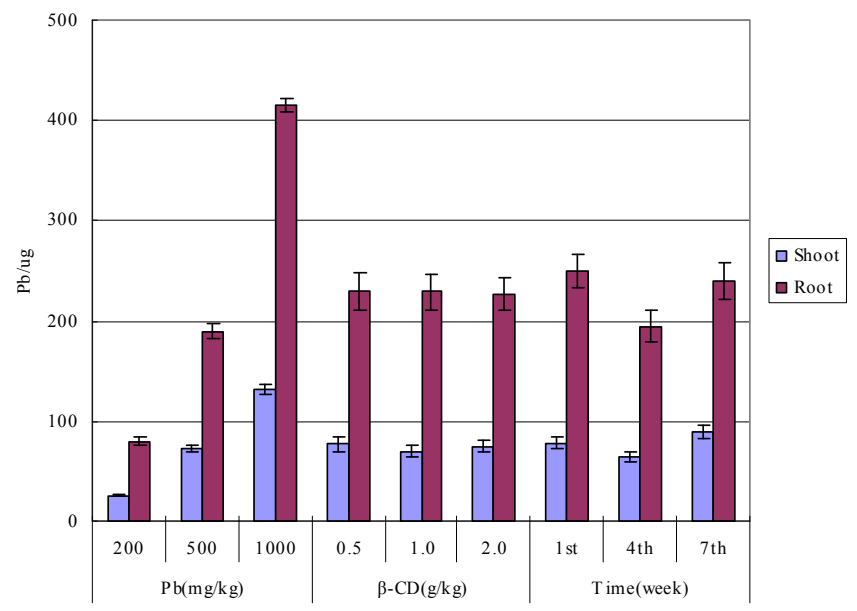

Figure 3. Effect of different factors on uptake amount of $\mathrm{Pb}$ in Brassica juncea. 


\section{CONCLUSION}

Effect of $\beta$-cyclodextrin on phytoremediation of $\mathrm{Pb}$-contaminated soil was investigated by Braasica juncea. Consequently, it also clearly indicates that $\beta$-cyclodextrin enhance the phytoremediation effect of $\mathrm{Pb}$-contaminated soil to some extent, which is related to the addition dosage and addition time of $\beta$-cyclodextrin as well as $\mathrm{Pb}$ concentration in soil.

\section{ACKNOWLEDGEMENTS}

The present work was supported and funded by the overseas scholar scientific research project from the department of education of Heilongjiang province, China.

\section{REFERENCE}

[1] Li, J.M. et al. 2007. "Influence of EDTA application on the growth and lead accumulation of mustard seedlings planted in Pb-contaminated soils," Chinese Journal of Soil Science, 38(6), 11781181.

[2] Lin, C.C. et al. 2009. "Soil amendment application frequency contributes to phytoextraction of lead by sunflower at different nutrient levels," Environmental and Experimental Botany, 65(2-3) 410-416.

[3] Magdalena, P.P. et al. 2011. "Environmental applications of biosurfactants: recent advances," International Journal of Molecular Sciences, 12, 633-654, doi: 10.3390/ijms12010- 633.

[4] Ma, Y. et al. 2011. "Plant growth promoting rhizobacteria and endophytes accelerate phytoremediation of metalliferous soils," Biotechnology Advances, 29(2), 248-258.

[5] Nicoletta, R. \& Flavia, N.I. 2011. "Heavy metal hyperacc-umulating plants: How and why do they do it? And what makes them so interesting?" Plant Science, 180(2), 169-181.

[6] Saifullah, E.M. et al. 2009. "EDTA-assisted Pb phytoextr- action," Chemosphere, 74, 12791291. 